www.jmscr.igmpublication.org

Impact Factor 3.79

ISSN (e)-2347-176x ISSN (p) 2455-0450

crossref DOI: _http://dx.doi.org/10.18535/jmscr/v3i10.63

\title{
An Open Label, Prospective, Single Center Study to Evaluate the Efficacy of Methyldopa \& labetalol in Treatment of Patients with Pregnancy-induced hypertension
}

\author{
Author \\ Dr Deepanjali Lomte \\ Assoc. Prof. Dept. of Pharmacology
}

\begin{abstract}
Background: Pregnancy-induced hypertension is associated with various adverse fetal and maternal outcomes. The use of anti-hypertensive drugs in pregnancy is controversial. We conducted a prospective study to evaluate the comparative effectiveness and safety of methyldopa and labetalol monotherapy in patients with pregnancy-induced hypertension.
\end{abstract}

Objective: To compare the efficacy \& safety of Methyldopa and Labetalol on Blood pressure in Pregnancyinduced hypertension (PIH) patients.

Methods: Patients $n=60$ pregnant women with blood pressure of $140 / 90 \mathrm{~mm} \mathrm{Hg}$ or more with $\geq 1+$ proteinuria and gestational age between 20-38 weeks were included in this prospective study. Cases were randomly divided into two groups of 30 each. Group -I received methyldopa $(n=30)$ and Group II received labetalol $(n=20)$. Blood pressure was measured at 0, 6, 24, 48 and $72 \mathrm{~h}$ of initiation of antihypertensive drugs. Patients were also followed up for development of adverse drug effects during this period.

Results: Antihypertensive treatment with methyldopa was associated with reduction in systolic blood pressure (SBP) by $54 \mathrm{mmHg}$ and diastolic blood pressure $(\mathrm{DBP})$ by $30 \mathrm{mmHg}$ at $72 \mathrm{~h}$. For the same period treatment with labetalol was associated with reduction in SBP by $70 \mathrm{mmHg}$ and DBP by $36 \mathrm{mmHg}$ at $72 \mathrm{~h}$.

Conclusions: Labetalol was more effective than methyldopa in controlling blood pressure in patients with pregnancy-induced hypertension.

Keywords: Antihypertensive, Pregnancy-induced hypertension(PIH), Pre-eclampsia, Methyldopa, Labetalol.

\section{INTRODUCTION}

Hypertensive disorders are the most common medical complications of pregnancy and are important causes of maternal and perinatal morbidity and mortality. Hypertension during pregnancy had been described in ancient literature as well. ${ }^{1}$ Preeclampsia, a life threatening complication of pregnancy is a condition that typically starts after 20th week of pregnancy and is related to increase blood pressure $(\mathrm{BP} \geq 140 / 90$ $\mathrm{mmHg}$ ) and protein in mother's urine (urinary albumin protein $\geq 300 \mathrm{mg} / 24 \mathrm{~h}$ ). Preeclampsia occurs in $5-8 \%$ of pregnancies worldwide, and is the second leading cause of direct maternal and fetal deaths. ${ }^{2}$ Hypertensive disorders during pregnancy are classified into 4 categories, as 
recommended by the National High Blood Pressure Education Program Working Group on High Blood Pressure in Pregnancy: 1) chronic hypertension, 2) preeclampsia-eclampsia, 3) preeclampsia superimposed on chronic hypertension, and 4) gestational hypertension (transient hypertension of pregnancy or chronic hypertension identified in the latter half of pregnancy) ${ }^{3}$

The etiology of preeclampsia is still obscure, despite many attempts to identify possible causes. The clinical spectrum of preeclampsia ranges from mild to severe. Women with mild preeclampsia generally have no symptoms. Women with severe pre-eclampsia, or with very high blood pressure, may feel unwell, with symptoms such as headache, upper abdominal pain, or visual disturbances. ${ }^{4}$ Pregnancies complicated by hypertension are associated with increased risk of adverse fetal, neonatal and maternal outcomes, including preterm birth, intrauterine growth restriction (IUGR), Perinatal death, acute renal or hepatic failure, antepartum haemorrhage, postpartum haemorrhage and maternal death ${ }^{5}$

The major goal of antihypertensive medication in $\mathrm{PIH}$ is to prevent or treat severe hypertension (generally defined as Blood Pressure (BP)of $\geq 160 / 110 \mathrm{mmHg}$ ) and its associated complications and to prolong pregnancy for as long as possible. ${ }^{6}$ The antihypertensive drugs that may be used in pregnancy are methyldopa, beta blockers, calcium channel blockers and vasodilators. Methyldopa has been available for many years and is widely used. $^{7-12}$

The purpose of this study was to evaluate the comparative effectiveness and safety of methyldopa and labetalol monotherapy in patients with pregnancy-induced hypertension (PIH).

\section{MATERIALS AND METHODS}

\section{Study Design:}

It was an open labeled, prospective, randomized, parallel and single center study.

\section{Inclusion Criteria:}

1. Pregnant women aged $\geq 18$, gestational week between 20 and 38 weeks with blood pressure of $140 / 90 \mathrm{~mm} \mathrm{Hg}$ or more and $\geq 1+$ proteinuria with urine dipstick test.

2. Pregnant women willing to give confirm consent for the study

\section{Excusing Criteria:}

1. Pregnant women with underlying chronic hypertension, history of antihypertensive medication in the current pregnancy \& secondary hypertension.

2. Patients with molar pregnancies, multiple pregnancy, placenta previa.

3. Pregnant women with congenital anomalies, renal disease, hematological disease, heart disease and Diabetes.

After the approval of Institutional Ethics committee of Dr VPMC, Nashik, total 60 antenatal women with $\mathrm{PIH}$, who first presented between 20 and 38 weeks of gestation \& attending the outpatient department \& antenatal ward at Civil Hospital Nashik, were included in the present study. The study was carried out during June 2011 to Jan.2012.Informed consent was obtained from all the patients before enrollment. Medical and obstetric history taking and physical examination were performed at the time of initial recruitment. Conventional sphygmomanometer was used for BP measurement and phase $\mathrm{V}$ Koratokoff sounds were used to define diastolic BP. The measurements were taken in the sitting position in a chair after 30 minutes rest. Urinary protein excretion was measured with urine dipstick test.

All the 60 cases enrolled in the study were randomly allocated into two groups. Group -I received Methyldopa $(\mathrm{n}=30)$ and Group II received Labetalol $(\mathrm{n}=30)$. Methyldopa was started at a dose of $250-500 \mathrm{mg}$ twice daily while Labetalol was started at a dose of 100-400mg twice daily. .All the patients were followed for $72 \mathrm{hr}$. Blood pressure was measured at 0, 6, 24, 48 


\section{JMSCR VoI||3||Issue||10||Page 8113-8118||October}

and $72 \mathrm{hr}$ of initiation of antihypertensive drugs. Patients were also followed up for development of adverse drug effects during this period. Blood pressure data are presented diverse drug effects during this period. Blood pressure data are presented as mean for both treatment groups.

\section{RESULTS}

A total of 60 eligible patients were randomized to receive methyldopa $((n=30)$, Or labetalol $((n=30)$. Both groups had comparable baseline and demographic characteristics. The changes in systolic blood pressure (SBP) and diastolic blood pressure (DBP) are shown in figure 1 and figure 2 respectively.

\section{Figure I}

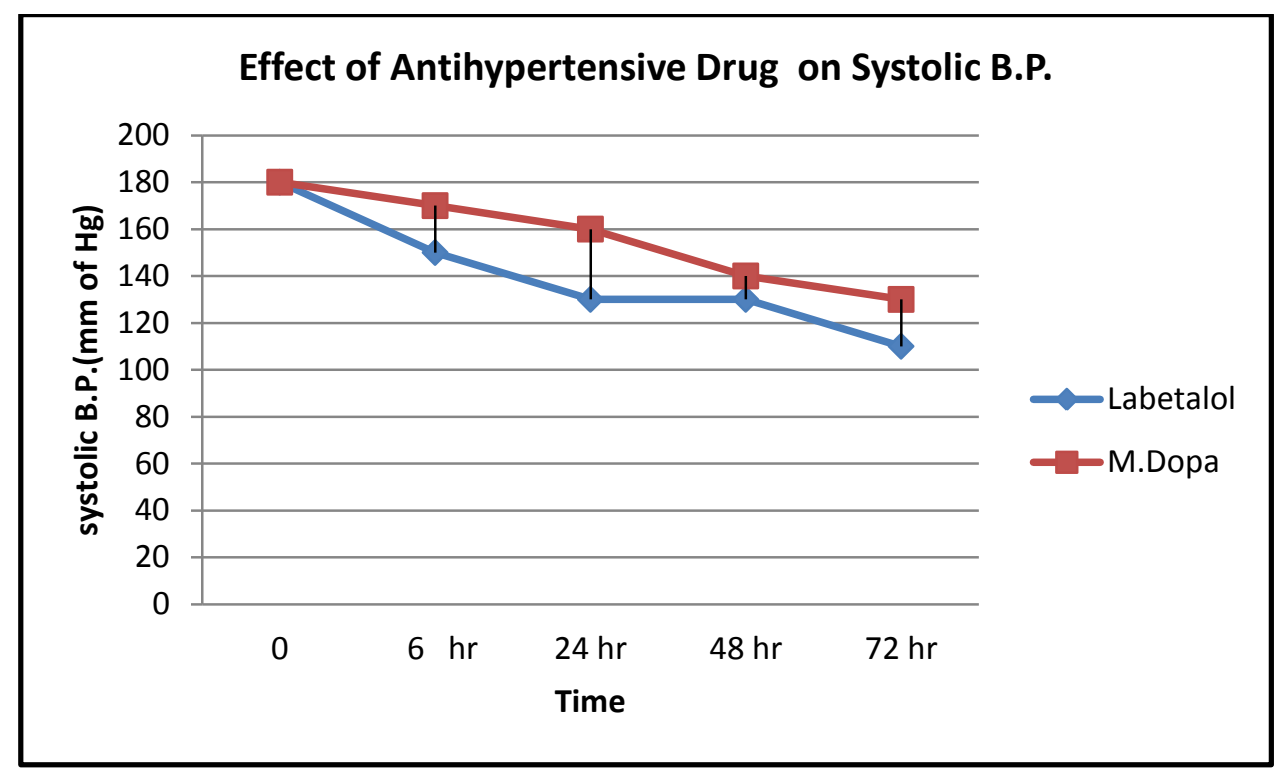

Figure II

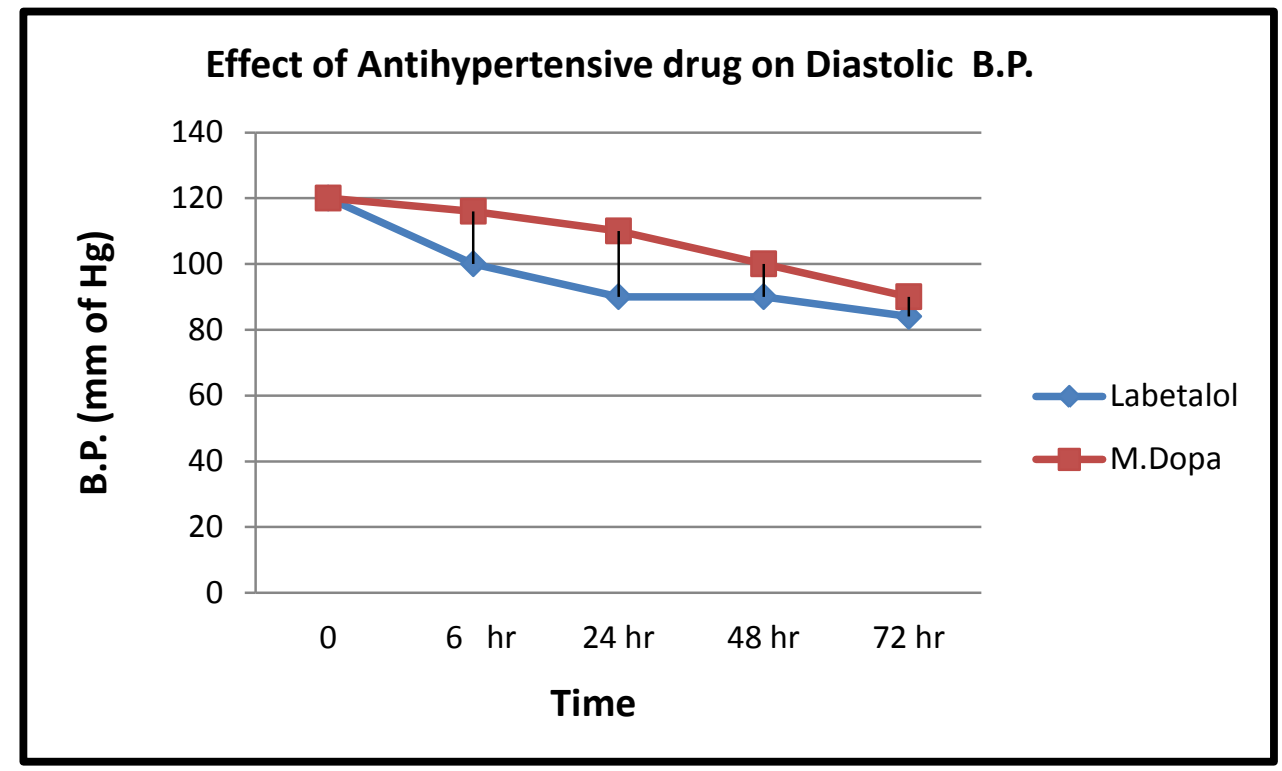


Figure III

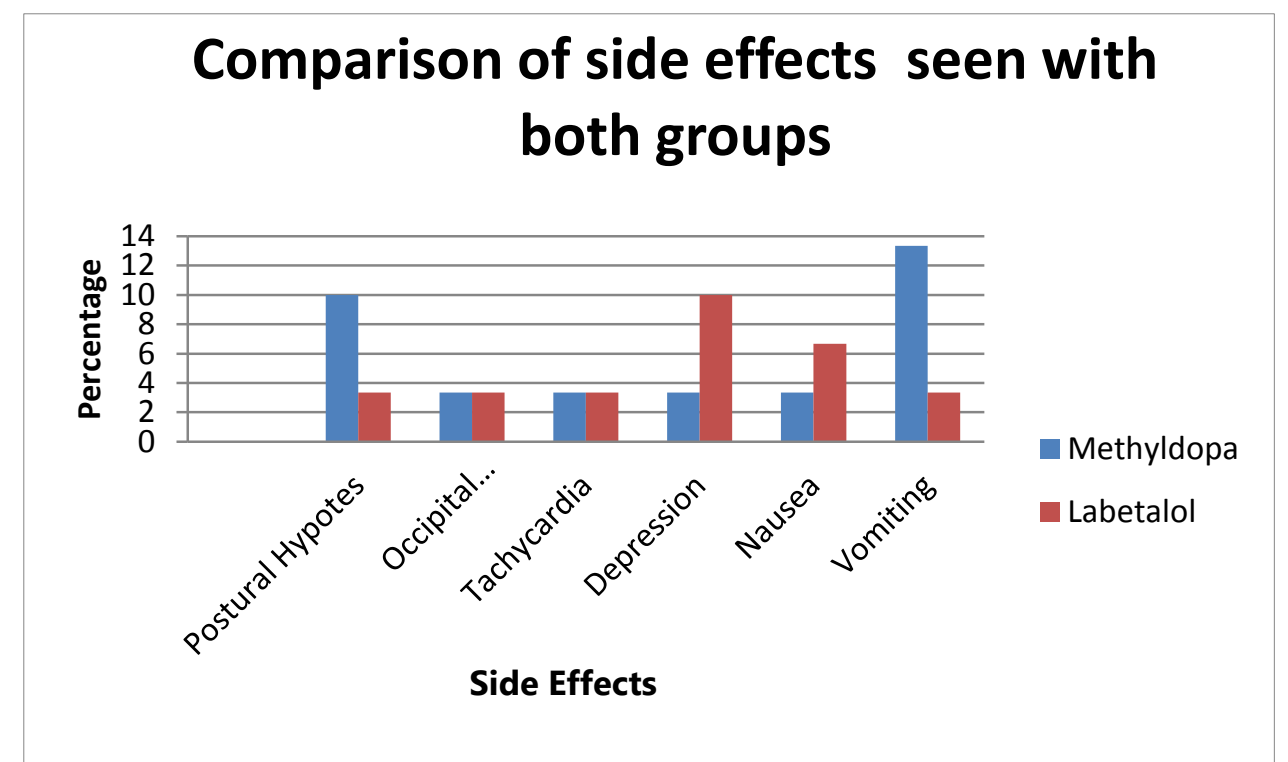

Antihypertensive treatment with methyldopa was associated with reduction in systolic BP by 50 $\mathrm{mmHg}$ and diastolic BP by $30 \mathrm{mmHg}$ at $72 \mathrm{~h}$. For the same period treatment with labetalol was associated with reduction in systolic BP by 70 $\mathrm{mmHg}$ and diastolic BP by $36 \mathrm{mmHg}$ at $72 \mathrm{hr}$. The common adverse effects reported are shown in figure 3. The commonest adverse effects noted were occipital headache (3-\%), postural hypotension (3-8\%), tachycardia (2-3\%), and depression (2-7\%), nausea \& vomiting. Depression was more common with both groups. Postural hypotension (10\%) and vomiting (12\%) were more commonly reported side effects with methyldopa group.

\section{DISCUSSION}

Pregnancy-induced hypertension is one of the major causes of maternal and foetal mortality and morbidity and as long as its exact cause is unknown, its prophylaxis will be uncertain. Many drugs have been used in the management of PIH in pregnancy.

The results of the present study demonstrate that antihypertensive drugs were very effective in reduction of systolic and diastolic blood pressure. In the past an increasing variety of hypertensive drugs have been used in treatment of PIH.

Unlike this study where two different antihypertensive drugs were effective as
Monotherapy in controlling blood pressure other reports indicate the addition of another antihypertensive to control the blood pressure is frequently required.

One of the studies found it necessary to add hydralazine to both treatment regimens of oxprenalol and methyldopa for improved blood pressure control. $^{12}$

Combination drug therapy confuses an already complex condition involving the mother and the foetus.The reported effects of antihypertensive drugs on the placental circulation and therefore oxygenation of the fetus are conflicting. One of the studies has reported a two-thirds incidence of small, for gestation age, infants born to women on oral antihypertensive drugs. ${ }^{13}$

Unlike other antihypertensive drugs labetalol reduces peripheral resistance without significantly reducing maternal cardiac output and pulse rate. This may be an additional factor in maintaining adequate placental perfusion and therefore foetal oxygenation in the treatment of pregnancy hypertension with labetalol.

Methyldopa is probably the most frequently used antihypertensive drug in pregnancy. Data suggest that the treatment of maternal hypertension with methyldopa may reduce the head circumference of infants where the drug has been prescribed between 16 and 20 weeks gestation. ${ }^{14}$ 
This may be the sensitive period for brain growth. This study confirms the previous Findings that labetalol is an effective and safe drug for use in the control of blood Pressure in pregnancyinduced hypertension. The low incidence of maternal and foetal side-effects together with the excellent prenatal outcome in a condition usually accompanied by a high maternal and foetal mortality and morbidity confirms its suitability for use during pregnancy. ${ }^{19}$

The low incidence of pulmonary hyaline membrane disease suggests that it is the Preferred drug in the treatment of pregnancy-induced hypertension. ${ }^{15}$

\section{CONCLUSION}

The results of the present study concluded that both Methyl Dopa \& labetalol are effective in controlling blood pressure in patients with PIH.But labetalol is more effective than methyldopa in controlling blood pressure in patients with Pregnancy - induced hypertension.

\section{REFERENCES}

1. Chesney LC. History. In Chesney LC (Ed): Hypertensive disorders in pregnancy. New York, Appleton, Century, Crofts, 1978: 17034.)

2. Roberts JM, Lain KY: Recent insights into the pathogenesis of pre- eclampsia. Placenta 2002, 23: 359-72. )

3. Duley L: Maternal mortality associated with hypertensive disorders of pregnancy in Africa, Asia, Latin America and the Caribbean. Br J Obstet Gynaecol 1992, 99:547-553. )

4. Pregnancy. American Journal of Obstetrics and Gynecology 1990; 163: 1691 - 1712.

5. Ching-Ming Liu, Po- jen Cheng, SheuennDyh Chang. Maternal Complications and Perinatal Outcomes associated with Gestational Hypertension and Severe Preeclamsia in Taiwanese Women. Journal
Formes Medical Association 2008; 107(2):129-138.

6. ACOG Committee on Obstetric Practice. ACOG practice bulletin. Diagnosis and management of preeclampsia and eclampsia. Number 33, January 2002. American College of Obstetricians and Gynecologists. Int $\mathbf{J}$ Gynaecol Obstet 2002; 77:67 -75

7. Giannubilo SR, Bezzeccheri V, Cecchi S, Landi B, Battistoni GI, Vitali P, Cecchi L, Tranquilli AL. Nifedipine versus labetalol in the treatment of hypertensive disorders of pregnancy. Arch Gynaecol Obstet 2012; 286:637-42.

8. El-Qarmalawi AM, Morsy AH, Al-Fadly A. Labetalol vs. methyldopa in the treatment of pregnancy-induced hypertension. Int J Gynaecol Obstet 1995;49: $125-30$.

9. Khedun SM, Moodley J, Naicker T. Drug management of hypertensive disorders of pregnancy. Pharmacol Ther 1997; 74:22158.13.Mabie WC. Management of acute severe hypertension and encephalopathy. Clin Obstet Gynaecol 1999; 42:519-31.

10. Linton DM, Anthony J. Critical care management of severe pre-eclampsia. Intensive Care Med 1997; 23:248-55.

11. Lamming GD, Broughton Pipkin F, Symonds EM. Comparison of the alpha and beta blocking drug, labetalol, and methyl dopa in the treatment of moderate and severe pregnancy-induced hypertension. Clin Exp Hypertens 1980; 2:86595.

12. Gallery ED, Saunders DM, Hunyor SN, Gyory AZ. Randomized comparison of methyldopa and Oxprenolol for treatment of hypertension in Pregnancy. Br Med J 1979; 1(6178):1591-4.

13. Welt SI, Dorminy JH 3rd, Jelovsek FR, Crenshaw MC, Gall SA. The effects of prophylactic Management and therapeutics on hypertensive Disease in pregnancy: 
preliminary studies. Obstet Gynaecol 1981; 57:557-65.

14. Ounsted MK, MoarVA, Good FJ, Redman CW. Hypertension during pregnancy with and without Specific treatment; the development of the children At the age of four years. Br J Obstet Gynaecol 1980; 87:19-24.

15. Michael CA. The evaluation of labetalol in the Treatment of hypertension complicating pregnancy. $\mathrm{Br} \mathrm{J}$ Clin Pharmacol 1982; 13(1 Suppl):127S-131S 